\title{
Keeping the Board in the Dark: \\ CEO Compensation and Entrenchment*
}

\author{
Roman Inderst $^{\dagger} \quad$ Holger M. Mueller ${ }^{\ddagger}$
}

September 2005

\begin{abstract}
We study a model in which a CEO can entrench himself by hiding information from the board that would allow the board to conclude that he should be replaced. Assuming that even diligent monitoring by the board cannot fully overcome the information asymmetry visà-vis the CEO, we ask if there is a role for CEO compensation to mitigate the inefficiency. Our analysis points to a novel argument for high-powered, non-linear CEO compensation such as bonus pay or stock options. By shifting the CEO's compensation into states where the firm's value is highest, a high-powered compensation scheme makes it as unattractive as possible for the CEO to entrench himself when he expects that the firm's future value under his management and strategy is low. This, in turn, minimizes the severance pay needed to induce the CEO not to entrench himself, thereby minimizing the CEO's informational rents. Amongst other things, our model suggests how deregulation and technological changes in the 1980s and 1990s might have contributed to the rise in CEO pay and turnover over the same period.
\end{abstract}

${ }^{*}$ We thank Andres Almazan, James Dow, Dirk Jenter, Wei Jiang, Lasse Pedersen, Thomas Phillipon, Javier Suarez, Jeff Wurgler, David Yermack, and seminar participants at Stanford University, UC Berkeley, University of Pennsylvania, New York University, University of Southern California, London Business School, London School of Economics, CEMFI, HEC, the European Summer Symposium in Financial Markets in Gerzensee (2005), and the NBER Corporate Finance Meeting in Cambridge (2005) for helpful comments and suggestions.

${ }^{\dagger}$ London School of Economics and CEPR. Address: Department of Economics and Department of Finance, London School of Economics, Houghton Street, London WC2A 2AE. Email: r.inderst@lse.ac.uk.

${ }^{\ddagger}$ New York University and CEPR. Address: Department of Finance, Stern School of Business, New York University, 44 West Fourth Street, Suite 9-190, New York, NY 10012. Email: hmueller@stern.nyu.edu. 
$[\mathrm{M}]$ any CEOs still take the "mushroom" approach to their boards: Keep them in the dark and cover them with manure.

James E. Orlikoff

\section{Introduction}

The decision to replace the CEO is arguably one of the most important decisions made by the board of directors. Yet, to make this decision the board needs information-information that is often controlled by the very CEO it is supposed to judge. The CEO's control over information in the boardroom thus puts a natural limit on the board's ability to effectively monitor him: "[T]he CEO most always determines the agenda and the information given to the board. This limitation severely hinders the ability of even highly talented board members to contribute effectively to the monitoring of the CEO and the company's strategy" (Jensen (1993)). ${ }^{1}$

Most efforts to improve boards' monitoring effectiveness have focused on the board itself, e.g., by increasing the number of outsiders on boards or by including board members with financial expertise. As empirical studies show, however, the effects of these changes on performance are modest. ${ }^{2}$ Indeed, if it is true that even "highly talented board members" cannot fully overcome the information asymmetry vis-à-vis the CEO, then this may not surprise. After all, there may be a natural limit as to what can be accomplished through monitoring.

On a priori grounds, there is no reason why efforts to improve boards should be limited to the board in a narrow sense. In the end, any institution or governance instrument that can help mitigate the information asymmetry vis-à-vis the CEO will also make the board a better monitor. Starting from this premise, we focus on a governance instrument that, like the board of directors, has received much attention recently: executive compensation. To study the role of executive compensation in mitigating the information disparity between the board and the CEO, we assume the board cannot actively reduce this disparity any further through additional monitoring. Hence, when the board makes a decision it must rely on information that is provided

\footnotetext{
${ }^{1}$ Similarly, Coffee (2003) argues that "one must look beyond the board, in particular to those who provide or control its informational inputs".

${ }^{2}$ See Hermalin and Weisbach (2003) for a survey of the empirical literature. The trend towards board members with greater expertise has recently manifested itself in Section 101 of the Sarbanes-Oxley (2002) Act, which stipulates that "[t]he board will have five financially-literate members."
} 
by the CEO. What this means, of course, is that the CEO can effectively control the board's decision through his strategic choice of what information to provide.

To fix ideas, we consider a model in which the board must decide whether to replace the incumbent CEO. We model the information asymmetry between the board and the CEO by assuming that prior to the board meeting the CEO privately observes the "state of nature", which is a noisy signal of the firm's future value under his strategy and management. The term "state of nature" is sufficiently general to admit alternative interpretations. Perhaps the most natural interpretation is that it constitutes a signal of the CEO's ability to create value at this particular job in this particular firm. In that sense, the state of nature is a proxy for the match quality between the firm and the CEO, like in Hermalin and Weisbach (1998) and Hermalin (2004). ${ }^{3}$ Another interpretation is that the CEO is hired to implement a particular business strategy (e.g., he is hired because of his reputation as a cost-cutter), and he privately observes an early signal indicating the likely success of this strategy. If the CEO's tenure is closely linked to this particular strategy then he has an incentive to hide information suggesting that the strategy should be changed. ${ }^{4}$

Our assumption that the board must rely on the CEO's information to make its replacement decision suggests that the CEO can easily entrench himself by hiding negative information that would allow the board to conclude that he should be replaced. Indeed, absent any countervailing incentives, this is precisely what the CEO would do, for he is biased in favor of staying in powera bias that arises endogenously in our model. It is therefore immediate that any optimal CEO compensation package must include some form of severance pay or a golden parachute; otherwise the CEO would always entrench himself. ${ }^{5}$

\footnotetext{
${ }^{3}$ In both models the board can acquire a noisy signal about the CEO's match-specific quality while the CEO cannot directly influence the board's information. In contrast, in our model the board cannot improve its information set any further but must instead rely on information provided by the CEO.

${ }^{4}$ The management literature provides ample evidence that strategy changes are often accomplished by hiring a new CEO (e.g., Hambrick, Geletkanycz, and Fredrickson (1993), Barker and Duhaime (1997), Gordon et al. (2000)). Relatedly, Rotemberg and Saloner (2000) argue that hiring a CEO with a particular vision and style is a credible signal to the firm's employees that the firm will pursue a particular strategy.

${ }^{5}$ The use of golden parachutes or severance pay to induce CEOs to give up their power has been previously examined in, e.g., Lambert and Larcker (1985), Harris (1990), and Almazan and Suarez (2003). What both Almazan and Suarez (2003) and our paper show is that severance pay and on-the-job compensation may be related in equilibrium.
} 
Offering the CEO severance pay is only one side of the coin, however. When considering whether or not to entrench himself, the CEO compares the value of his severance package with the expected value of his on-the-job compensation that he receives if he remains in power. This suggests that the CEO's on-the-job compensation scheme should force him to "put his money where his mouth is": if he contends that the firm's future value under his management and strategy is high, then he should be rewarded generously if this turns out to be true but punished (subject to limited liability) if it does not. By this reasoning, the CEO's optimal compensation scheme should shift as much as possible of his on-the-job compensation into states where the firm's future value is highest. In our base model, where we impose only little structure on the optimal compensation scheme, this implies that the CEO's optimal on-the-job compensation scheme is a high-powered, discontinuous bonus scheme. If we impose more structure, the precise functional form of the CEO's optimal on-the-job compensation scheme may change, but not the basic principle that as much as possible of the CEO's compensation should be shifted into states where the firm's value is highest. To obtain more structure, we consider a simple problem in which the CEO can manipulate the firm's future share value. In this case, his optimal on-thejob compensation scheme becomes a stock option. The economic principle underlying the result remains the same, however.

In summary, a high-powered, non-linear on-the job compensation scheme is optimal in our model as it minimizes the CEO's expected on-the-job compensation in states of nature where the firm's expected future value under his strategy and management is low. Consequently, less severance pay is needed to induce the CEO to give up power in such states. In our model, severance pay constitutes a measure of the CEO's informational rents. Hence, a high-powered, non-linear compensation scheme minimizes the CEO's informational rents. Incidentally, while we focus on information-based entrenchment where the CEO can assure his retention by hiding negative information, it is not critical for our results that the CEO has better information at the board meeting. As we will show, our model is isomorphic to one in which both the CEO and the board know the true state of nature at the board meeting but the CEO learns it before the board does. Instead of hiding negative information - which is now no longer possible by assumptionthe CEO can, after observing a low state of nature, make an irreversible "protective" investment that makes it suboptimal for the board to subsequently replace him, as in Shleifer and Vishny (1989) or Scharfstein and Stein (2000). All our results continue to hold under this alternative 
notion of entrenchment.

While our analysis suggests that it is optimal to combine severance pay with high-powered, non-linear on-the-job compensation, it also suggests that there is a delicate balance between these two instruments. If one or the other is set too high, the CEO will either always prefer to entrench himself or he will shirk and inefficiently focus on his exit options. Moreover, our analysis implies that the CEO's on-the-job compensation and severance pay must move in the same direction. ${ }^{6}$ Finally, while a combination of severance pay and high-powered on-the-job compensation is the least-cost way of mitigating the CEO's entrenchment in our model, it remains costly. For this reason, it is only optimal to mitigate, but not fully eliminate, the CEO's entrenchment.

Our result that a combination of severance pay and high-powered on-the-job compensation minimizes information-based entrenchment is novel and, we believe, intuitive. It is arguably different from existing arguments for high-powered CEO compensation based on moral hazard (Innes (1990)) or risk-taking (Lambert (1986)). Our analysis also cautions that observing generous high-powered compensation packages in firms where boards are weak does not automatically imply that executives divert wealth from shareholders (cf., Bebchuk and Fried (2004)). On the contrary, such packages may well be part of an optimal arrangement that is in place precisely because monitoring by the board is ineffective. ${ }^{7}$

As we stated above, our model admits alternative interpretations. One such alternative interpretation concerns the firm's shutdown decision. Suppose instead of deciding whether to replace the CEO the board must decide whether to shut the firm down, in which case the CEO

\footnotetext{
${ }^{6}$ In a comprehensive legal study of CEO employment contracts in the U.S., Schwab and Thomas (2004) find that more than 93 percent of such contracts formally stipulate severance pay. In virtually all these cases, the size of the CEO's severance pay is linked to his on-the-job pay. The most common contractual award is two years' salary. The authors also dispense with the myth that CEOs in the U.S. are employed at will. The overwhelming majority of CEOs either have a formal employment contract or some other formal contractual arrangement governing issues that are otherwise found in employment contracts, such as severance pay. Relatedly, Lefanowicz, Robinson, and Smith (2000) find that managers whose employment contracts stipulate generous golden parachutes tend to be more highly compensated on their jobs. While Yermack (2004) also finds that severance pay is positively related to the CEO's on-the-job pay, his data includes-besides contractual severance pay - additional "golden handshakes" that are paid upon the CEO's departure.

${ }^{7}$ We have hitherto only argued with respect to the optimal form of executive compensation, not with respect to its magnitude. In Section 5 we show than in an environment where implementing change is important it may be optimal to grant CEOs potentially very generous compensation packages.
} 
naturally loses his job. The CEO again observes the state of nature, which is now a signal of the firm's future value if it is continued. For fear of losing his job, the CEO might then propose that the firm should be continued even if shutting down is efficient. This is precisely what Jensen (1993) views as a main obstacle to what he refers as "Modern Industrial Revolution": managers are reluctant to shut down their firms, thus impeding the efficient transfer of assets from old, declining industries to new, thriving industries. ${ }^{8}$ Given this alternative interpretation, our model implies that a combination of severance pay and high-powered on-the-job compensation is the least-cost way to get managers to accept the necessary shutdown of their firms. This is consistent with the observation by Mehran, Norgler, and Schwartz (1997) that option grants seem to have a positive effect on the likelihood of voluntary liquidation. It is also consistent with Dial and Murphy's (1995) clinical study of General Dynamic's partial liquidation, where stock option programs helped to overcome managers' resistance against liquidating plants and selling off assets, even if this meant that they had to sacrifice their own jobs.

In the final part of this paper we derive additional testable implications. For instance, we find that when the ex-ante likelihood that a strategy change becomes optimal increases - like in the 1980s and 1990s when massive technological changes and deregulations fundamentally changed the industrial landscape in the U.S. - then both the level of CEO compensation and CEO turnover should increase correspondingly. This is consistent with the widely documented surge in executive compensation, especially incentive pay, during the 1980s and 1990s (Hall and Liebman (1998), Bebchuk and Grinstein (2005)) as well as Huson, Parrino, and Starks' (2001) finding that CEO turnover has increased over the past decades. Another implication of our model is that CEOs of larger firms should receive both higher on-the-job compensation and higher severance pay, while at the same time CEO turnover should also be higher. Yet another implication is that in firms with weak corporate governance-defined as firms where it is relatively easier for CEOs to shirk or appropriate private benefits - we should see both higher severance pay and higher CEO on-the-job compensation, but also more entrenchment.

Several recent papers examine issues that are related to our paper. We will review these papers in the next section as well as in Section 5 when we discuss additional implications of our model. The rest of this paper is organized as follows. Section 3 presents the model. Section

\footnotetext{
8 "Even when managers do acknowledge the requirement for exit, it is often difficult for them to accept and initiate the shutdown decision" (Jensen (1993)).
} 
4 contains our main analysis. Section 5 derives additional testable implications. Section 6 concludes. All proofs are in the Appendix.

\section{Related Literature}

To put our paper into perspective, it is helpful to recall its main features. First, the inefficiency we are concerned with is that low-quality CEOs may not get replaced. (Or, alternatively, that unsuccessful firm strategies may not get changed). Second, the reason for this inefficieny is that the CEO has private information vis-à-vis the board. Third, assuming that monitoring by the board cannot fully resolve this ineffiency, we ask if there is a role for other corporate governance instruments. Specifically, our focus here is on executive compensation.

While the papers discussed below are all related to ours, only two papers share our focus on optimal executive compensation design: Almazan and Suarez (2003) and Dow and Raposo (2005). In both papers, the CEO's optimal on-the-job compensation scheme is a bonus scheme, like here. The rationale is different, however. In these papers a bonus scheme is optimal because the CEO must be motivated to exert effort or make an unobservable investment. ${ }^{9}$ By contrast, in our model a bonus scheme is optimal because it minimizes the CEO's (informational) rents if he is privately informed about the firm's future value under his management.

Hermalin and Weisbach (1998) and Hermalin (2004) consider the same inefficiency as this paper: CEOs that are a poor match for the firm may not get replaced. Unlike this paper, however, it is not the CEO but the board who obtains a private signal about the CEO's matchspecific quality. The focus is consequently on the board's endogenous monitoring decision, not on the CEO's decision to hide information from the board.

In Almazan and Suarez (2003), like here, the CEO can effectively veto his replacement ("weak board"). What is different is the underlying inefficiency, and hence the role of CEO compensation. There is no asymmetric information between the CEO and the board. As a consequence, the board's replacement decision is first-best efficient, regardless of the CEO's initial compensation contract. Rather than examining the (in)efficiency of the board's replacement decision, the authors focus on the impact that this decision has on the CEO's ex-ante incentives to create value. This leads to a novel argument for severance pay: severance pay creates a direct

\footnotetext{
${ }^{9}$ While our model also has a simple moral hazard problem, this problem has no direct implications for the CEO's optimal on-the-job compensation scheme (see Section 4.1).
} 
link between the CEO's payoff from renegotiations with the board and his ex-ante investment, which makes it a more effective, and hence cheaper, instrument to motivate the CEO than costly on-the-job incentive pay.

As we noted in the Introduction, we can alternatively interpret our model as one in which the CEO privately observes whether it is optimal to change the firm's strategy. In this regard, our paper is related to recent work by Dow and Raposo (2005) and Eisfeldt and Rampini (2004). In Dow and Raposo's model the CEO has private information with respect to available strategy choices, while the shareholders' problem is to get him to implement the strategy that is best for the firm given that they do not know what is available. While none of the available strategy choices involves the CEO's replacement, the CEO naturally chooses the strategy that yields him the highest rents, like in our model. In Eisfeldt and Rampini's model a manager has private information about the productivity of the assets under his control. To induce a low-productivity manager to relinquish control of his assets (in the extreme case: shut down the firm) - so that they can be used more productively elsewhere - shareholders must pay him a bonus, which is similar to the use of severance pay in our model.

Finally, in Adams and Ferreira (2003) the CEO must also decide whether to reveal information to the board. The information is about the firm itself, however, not about the CEO's ability, which is unknown to both the CEO and the board. The benefit of revealing information is that the board can give the CEO better advice; the cost is that it can monitor him with greater precision. Song and Thakor (2004) also consider the CEO's decision to reveal information to the board. The focus of their paper is on the board's advisory role, however, not its role as an institution deciding on the CEO's replacement. Assuming that neither side knows the other side's ability, the authors show how career concerns affect both the CEO's decision to pass on information to the board and the board's decision to approve ideas proposed by the CEO.

\section{The Model}

The model has three dates: $t=0,1$, and 2. In $t=0$ a firm hires a CEO. In $t=1$ the firm's board decides whether to retain or replace the CEO. Which of the two is optimal depends on the state of nature $\theta \in \Theta:=[\underline{\theta}, \bar{\theta}]$, which is privately observed by the CEO prior to the board meeting. The state of nature is a noisy signal of the firm's future value in $t=2$ under the CEO's management, which is denoted by $s \in S:=[\underline{s}, \bar{s}]$. We assume $\theta$ and $s$ are related via 
the conditional distribution function $G_{\theta}(s)$. The density function $g_{\theta}(s)$ is continuous in both $\theta$ and $s$, where $g_{\theta^{\prime}}(s) / g_{\theta}(s)$ is strictly increasing in $s$ for all $\theta^{\prime}>\theta$ in $\Theta$. Accordingly, high states of nature are good news for the firm's future value under the CEO's management in that they put more probability mass on high values of $s$ in the sense of the Monotone Likelihood Ratio Property (MLRP). ${ }^{10}$

The fact that the CEO privately observes the state of nature is meant to capture the fact that he has an informational advantage vis-à-vis the board with respect to information that is relevant for the replacement decision. ${ }^{11}$ For concreteness, let us assume $\theta$ is a noisy signal of the quality of the match between the CEO and the firm. If $\theta$ is high, the CEO is a good match and likely to generate a high future firm value, and vice versa. Initially, i.e., in $t=0$, everybody has common expectations about this match quality, which are expressed by the distribution function $F(\theta)$ with positive density $f(\theta)>0$ for all $\theta \in \Theta .{ }^{12}$ All distribution functions in our model are atomless.

Instead of assuming that $\theta$ is a signal of the match quality between the CEO and the firm, we could alternatively assume that it is a signal indicating how successful the firm's current strategy is. Accordingly, if $\theta$ is high, the firm's future value under the current strategy is likely to be high, and vice versa. If we additionally assume that the hiring of the CEO is directly linked to the firm's strategy (see Introduction), then a low value of $\theta$ implies that the CEO should optimally be replaced, just like above.

Realistically, whether the firm's future value under the CEO's management is high or low will not only depend on the CEO's match-specific quality, but also on whether the CEO is sufficiently dedicated to his job. For simplicity, we assume if the CEO shirks the state of nature is $\theta=\underline{\theta}$. As will become clear shortly, this assumption is stronger than what we need-all

\footnotetext{
${ }^{10} \mathrm{MLRP}$ is satisfied by many probability distributions (see Milgrom (1981)).

${ }^{11}$ We will show in Section 4.6 that our model can be alternatively interpreted as one in which both the board and the CEO know $\theta$ in $t=1$ but the CEO observes it before the board and can take appropriate actions to entrench himself. Although presumably realistic, it is thus not crucial that the CEO has better information in $t=1$ - it suffices if he learns the state of nature before the board does.

${ }^{12}$ Our assumption that the replacement decision depends on the match quality between the CEO and the firm and that everybody has initially common expectations about this match quality is similar to Hermalin and Weisbach (1998) and Hermalin (2004). While there is evidence consistent with the notion that CEOs vary according to their skills (Daines, Nair, and Kornhauser (2005)), our notion of match-specific quality alludes to the interaction between CEO skill and firm type, not CEO skill as such.
} 
we need is that if the CEO shirks the state of nature is sufficiently low so that replacing the CEO becomes optimal. If the CEO works hard to implement the firm's strategy we assume $\theta$ is generated by the distribution function $F(\theta)$ described above. We assume it is optimal to induce the CEO to work hard. ${ }^{13}$ This is costly, however: it means the CEO must forgo private benefits $B>0$. Whether or not the CEO works hard is unobservable.

Denote by $V>0$ the expected future firm value if the CEO is replaced. Realistically, this value will depend on the expected match quality between the firm and a potential replacement CEO. There is no need to make distributional assumptions about $V$. This is because the expected match quality between the firm and a potential replacement $\mathrm{CEO}$ is not informative (in a statistical sense) about the match quality between the firm and its current CEO.

We argued above that the term "state of nature" admits alternative interpretations. For instance, $\theta$ might be a noisy signal of how successful the firm's current strategy is. In this case, $V$ represents the firm's expected future value under the next best strategy alternative. ${ }^{14}$ Under a related but somewhat narrower interpretation, $\theta$ might be a noisy signal indicating whether it is optimal for the firm to continue or shut down, in which case the CEO naturally loses his job. In this case, $V$ represents the firm's liquidation value.

As a reference point, let us briefly consider the (first-best) optimal replacement decision if the state of nature was commonly observable and hence contractible. The optimal decision rule in this case is to retain the CEO if $E[s \mid \theta]:=\int_{S} g_{\theta}(s) d s \geq V$ and to replace him if $E[s \mid \theta]<V$. Ruling out trivial cases where the CEO is either retained or replaced in all states of nature, this implies there exists a unique interior cutoff state $\theta_{F B} \in(\underline{\theta}, \bar{\theta})$ such that the CEO is retained if

\footnotetext{
${ }^{13}$ In other words, the distribution function $F(\theta)$ holds along the equilibrium path where the CEO works hard. While admittedly simplistic, this effort problem is a parsimonious - perhaps the most parsimonious - way of creating a wedge between the CEO's severance pay and his expected on-the-job pay without having direct implications for the shape of his optimal on-the-job compensation scheme (see Section 4.1).

${ }^{14}$ While there is no reason why the CEO should have private information about the match quality between the firm and a potential replacement CEO, he might have private information about the firm's expected future value under the next best strategy alternative. In this case, it can be shown that the CEO should receive severance pay that is contingent on the firm's future value under this alternative strategy. Such payoff-contingent severance pay is, to the best of our knowledge, not observed in practice, however. Unless the CEO remains affiliated with the firm, e.g., as a member of the board, accelerating vesting provisions typically allow him to recoup the value from previously awarded stock or option grants, while other material rights are generally forfeited.
} 
and only if $\theta \geq \theta_{F B} \cdot{ }^{15}$

The crux with implementing the first best is that to make its decision the board must rely on information provided by the CEO. The focus of our analysis is on how the CEO's incentives to provide the board with information depend on his compensation structure. Denote the CEO's on-the-job compensation by $w(s) \leq s$, which implies it is a function of the firm's realized value in $t=2$. In contrast, if the $\mathrm{CEO}$ is replaced in $t=1$ he receives severance pay $W$. As we will show in Section 4.5, assuming that the CEO's compensation package takes the simple form assumed here - where $w(s)$ depends only on $s$ and where $W$ is a fixed payment - is without loss of generality. In fact, it is strictly optimal. ${ }^{16}$ To make the board's problem nontrivial, we assume it is optimal to replace the CEO in some but not all states of nature. ${ }^{17}$ If it was optimal to either replace or retain the CEO in all states of nature, the board would have no interest in eliciting the CEO's private information.

Finally, to keep the derivation of our main results as simple as possible, we assume that $w(s)$ is nondecreasing in $s$. This assumption is only for expositional convenience. As will become clear shortly, it will never be optimal to make $w(s)$ a decreasing function of $s$, i.e., the postulated constraint that $w(s)$ be nondecreasing does not bind at the optimal solution.

\section{Analysis}

\subsection{The Board's Problem}

Notice first that the board cannot pay the CEO a fixed wage $w(s)=w$ for all $s \in S$. If it did, the CEO would either always (i.e., for all $\theta \in \Theta$ ) or never want to stay in power depending on whether $w$ is greater or smaller than $W$. Arguably, if $w(s)=w=W$ the CEO is just indifferent. But if his on-the-job compensation is exactly equal to his severance pay, he has no incentives to work hard.

\footnotetext{
${ }^{15}$ As $G_{\theta}(s)$ satisfies MLRP, it satisfies First-Order Stochastic Dominance (FOSD), which implies $E[s \mid \theta]$ is strictly increasing in $\theta$. In conjunction with continuity of $g_{\theta}(s)$ in $\theta$, this implies there exists a unique interior cutoff $\theta_{F B}$ given by $E\left[s \mid \theta_{F B}\right]=V$.

${ }^{16}$ Precisely, we show in Section 4.5 that although the CEO has private information in $t=1$ it is not optimal to offer him a more complex menu of compensation schemes in which either $w(s)$ or $W$ depend nontrivially on $\theta$.

${ }^{17}$ This is optimal, for instance, if i) $E[s \mid \theta]$ is sufficiently greater than $V$ for high and sufficiently smaller than $V$ for low values of $\theta$, and if ii) $F(\theta)$ puts sufficient probability mass on both high and low values of $\theta$.
} 
Given that $w(s)$ is nondecreasing, ruling out $w(s)=w$ implies that the CEO's on-the-job compensation must be strictly increasing in $s$ for some $s \in S$ on a set of positive measure. In conjunction with the fact that $G_{\theta}(s)$ satisfies MLRP, this implies that his expected on-the-job compensation $E[w(s) \mid \theta]$ must be strictly increasing in $\theta$ for all $\theta \in \Theta$. We thus have the intuitive result that under any feasible compensation scheme the CEO's expected on-the-job compensation will be higher if the match quality between him and the firm is good.

In $t=1$ the CEO must decide what information to pass on to the board. Realistically, the CEO will provide the board with various pieces of information, some of which will be positive while others will be more negative. If the board makes its decision based on its beliefs about the CEO's match quality, then this implies that the CEO can move the board's decision in one direction or another by strategically holding back some of the more positive or negative information, respectively.

When deciding what information to reveal, the CEO compares his expected on-the-job compensation $E[w(s) \mid \theta]$ with his severance pay $W$. Since $E[w(s) \mid \theta]$ is strictly increasing and continuous in $\theta$, this implies there exists a unique interior cutoff value $\theta^{*}=\theta^{*}(w, W) \in(\underline{\theta}, \bar{\theta})$ given by

$$
E\left[w(s) \mid \theta^{*}\right]=W
$$

such that $E[w(s) \mid \theta] \geq W$ if and only if $\theta \geq \theta^{*}$. Note that while $\theta$ is a continuous variable, the CEO may provide the board only with coarse information. This is because the board's decision is a binary decision, implying that we can conveniently categorize any information provided by the CEO as either "positive" information resulting in his retention or "negative" information resulting in his replacement. We will come back to this issue in Section 4.5 when we consider general menus of the form $\{w(s, \theta), W(\theta)\}$.

Given that $E[w(s) \mid \theta] \geq W$ if and only if $\theta \geq \theta^{*}$, the CEO's optimal choice of information provision is as follows. If $\theta \geq \theta^{*}$ he provides the board with "positive" information resulting in his retention. As we discussed above, this means the CEO will strategically hold back information that could potentially trigger his replacement. On the other hand, if $\theta<\theta^{*}$ the CEO's severance pay is so high (or equivalently: the match quality is so poor) that he has no incentives to hide information. Hence, the board will (correctly) infer from the provided information that the state of nature is low and replace the CEO. ${ }^{18}$

\footnotetext{
${ }^{18}$ Technical note: in standard mechanism-design parlor, the categorization into "positive" and "negative" infor-
} 
We will show later that at the optimal solution it holds that $\theta^{*}<\theta_{F B}$. Accordingly, there exists a positive interval $\left[\theta^{*}, \theta_{F B}\right)$ where the CEO entrenches himself by hiding negative information even though (first-best) efficiency dictates that he should be replaced. We shall refer to $\left[\theta^{*}, \theta_{F B}\right)$ as the CEO's "entrenchment region".

We can now set up the board's maximization program to determine the CEO's optimal compensation package. The board chooses the CEO's on-the-job compensation $w(s)$ and his severance pay $W$ to maximize shareholders' expected payoff

$$
F\left(\theta^{*}\right)(V-W)+\int_{\theta^{*}}^{\bar{\theta}} E[s-w(s) \mid \theta] f(\theta) d \theta
$$

where $\theta^{*}$ depends on $w(s)$ and $W$ as described in (1). When designing the CEO's compensation package, the board must ensure that the CEO is sufficiently dedicated to his job. The CEO's expected payoff if he works hard is

$$
\int_{\theta^{*}}^{\bar{\theta}} E[w(s) \mid \theta] f(\theta) d \theta+F\left(\theta^{*}\right) W .
$$

On the other side, the CEO's payoff if he shirks is $B+W$. While shirking allows the CEO to consume his private benefits, it results in a low state of nature in which-given his optimal information strategy - he will be replaced.

Accordingly, the CEO works hard if and only if the term in (3) equals or exceeds $B+W$. Rearranging this inequality, we have that the CEO works hard if and only if

$$
\int_{\theta^{*}}^{\bar{\theta}} E[w(s)-W \mid \theta] f(\theta) d \theta \geq B,
$$

which implies there must be a sufficiently large wedge between the CEO's expected on-the-job compensation and his severance pay. While this wedge follows naturally from the fact that the CEO must be motivated to work hard, it has an important implication: it endogenously biases the CEO to remain in power. This bias to remain in power is what causes the CEO to entrench himself in situations when replacing him is efficient, which is the fundamental inefficiency we are concerned with in this paper.

\footnotetext{
mation employed here refers to an indirect mechanism. In the corresponding direct mechanism that we analyze the CEO truthfully announces $\theta$. What the above paragraph then says is that under any feasible direct mechanism it must hold that for all $\theta \geq \theta^{*}$ the $\mathrm{CEO}$ is retained and receives $w(s)$ while for all $\theta<\theta^{*}$ he is replaced and receives $W$. This follows immediately from the relevant truthtelling constraints in conjunction with the fact that $w(s)=w$ is not feasible.
} 
On the other side, the wedge implied by (4) has no immediate consequences for the shape of the CEO's optimal on-the-job compensation scheme $w(s)$. It merely requires that on averagei.e., across all "retention states" $\theta \geq \theta^{*}$ - the CEO's expected on-the-job compensation be sufficiently greater than his severance pay. But it says nothing about how precisely $w(s)$ should vary with $s$. This is important, for it implies that our results regarding the optimal shape of $w(s)$ are exclusively driven by concerns of how to reduce the CEO's entrenchment, not by concerns of how to get him to work hard. ${ }^{19}$

\subsection{The Optimal CEO Compensation Scheme}

The following observation follows from standard arguments.

Lemma 1. The incentive constraint (4) ensuring that the CEO works hard to implement the firm's strategy must hold with equality.

Rearranging (4) (with equality) shows that the CEO's expected compensation net of being compensated for his forgone private benefits $B$ equals

$$
\int_{\theta^{*}}^{\bar{\theta}} E[w(s) \mid \theta] f(\theta) d \theta+F\left(\theta^{*}\right) W-B=W .
$$

Consequently, the CEO extracts a rent equal to $W$ on top of being compensated for his forgone private benefits.

Proposition 1. The CEO earns a rent equal to the size of his severance pay.

To see what causes the board to leave the CEO a rent, recall that there must be a positive wedge between the CEO's expected on-the-job compensation and his severance pay. When offering the CEO severance pay, the board must consequently also increase his on-the-job compensation. Rearranging (4) yields

$$
\int_{\theta^{*}}^{\bar{\theta}} E[w(s) \mid \theta] \frac{f(\theta)}{1-F\left(\theta^{*}\right)} d \theta=W+\frac{B}{1-F\left(\theta^{*}\right)} .
$$

\footnotetext{
${ }^{19}$ Another way of seeing this is as follows. One can easily show that if $\theta$ is observable and contractible-in which case there is no entrenchment problem - there exist mechanisms satisfying (4) that implement the first best, including some where $w(s)$ takes the form of a fixed wage. An example is the mechanism whereby the CEO is retained if and only if $\theta \geq \theta_{F B}$, in which case his on-the-job compensation is $w=B /\left[1-F\left(\theta_{F B}\right)\right]$. (The CEO's severance pay is zero in this case.)
} 
Hence, if the board wants to raise the CEO's severance pay by, say, $\$ 1$ million it must raise his expected on-the-job compensation by the same amount. ${ }^{20}$ Regardless of whether the CEO is eventually replaced or not, he is thus better off by $\$ 1$ million.

The fact that severance pay constitutes a measure of the CEO's rents strikes us as a realistic implication of our model. It derives from the fact that the board cannot directly penalize the CEO for shirking because it cannot disentangle the different possible causes of a low state of nature. All it can do is replace the CEO. On the one side, the state of nature may be low because - despite working hard - the CEO is a poor match for the firm. On the other side, the state of nature may be low because the CEO has shirked. In the first case, severance pay constitutes a reward for the CEO not to entrench himself. In the second case, severance pay constitutes a "reward" for the CEO's shirking.

Also plausible, we believe, is the implication that an increase in the CEO's severance pay must be matched by a simultaneous increase in his on-the-job compensation. If the CEO's onthe-job compensation does not increase along with his severance pay, he will focus too much on his exit options, implying he will lack incentives to work hard to implement the firm's strategy.

In summary, granting the CEO severance pay is costly as it leaves him rents. However, without severance pay the CEO would always entrench himself because his expected on-thejob compensation is positive - even if $W=0$ - as he must be compensated for forgoing private benefits. (This can be seen by setting $W=0$ in (6).) Hence, without severance pay we would have $\theta^{*}=\underline{\theta}$.

Inserting (4) (with equality) into (2), the board's objective function becomes

$$
\int_{\theta^{*}}^{\bar{\theta}} E[s \mid \theta] f(\theta) d \theta+F\left(\theta^{*}\right) V-B-W .
$$

Writing the board's objective function this way illustrates that the board has two (conflicting) objectives. The first three terms in (7) represent the total surplus created, implying the board will try to maximize efficiency. Specifically, since $E[s \mid \theta]-V$ is negative and decreasing in $\theta$ if $\theta<\theta_{F B}$ and positive if $\theta>\theta_{F B}$, the board will try to push $\theta^{*}$ up as close as possible towards $\theta_{F B}$, thus minimizing the CEO's entrenchment region $\left[\theta^{*}, \theta_{F B}\right)$. On the other hand, the final term in (7) implies that the board will seek to minimize the CEO's severance pay $W$ and therefore his rents.

\footnotetext{
${ }^{20}$ Precisely, the left-hand side in (6) denotes the CEO's expected on-the-job compensation conditional on staying on the job.
} 
Given the board's objective function, we can now formally derive the CEO's optimal compensation package. Note first that any optimal compensation package must include severance pay. If $W$ were equal to zero the CEO would never be replaced. As for the CEO's optimal on-the-job compensation scheme $w(s)$, we can state the board's problem in two equivalent ways. Holding the CEO's severance pay $W$ fixed, the optimal on-the-job compensation scheme must maximize the cutoff value $\theta^{*}$. Conversely, holding the cutoff value $\theta^{*}$ fixed, the optimal on-thejob compensation scheme must minimize the CEO's severance pay $W$. One problem is the dual of the other. We obtain the following result.

Proposition 2. The uniquely optimal CEO compensation package consists of severance pay and a bonus scheme that pays $w(s)=0$ if $s<\hat{s}$ and $w(s)=s$ if $s \geq \hat{s}$ for some $\hat{s} \in(\underline{s}, \bar{s})$.

Proof. See Appendix.

Proposition 2 shows that the CEO's optimal on-the-job compensation scheme is a highpowered, non-linear bonus scheme that shifts all of his on-the-job compensation into states where the firm's value $s$ is highest. In turn, the CEO receives nothing when $s$ is low. The intuition is straightforward. As low firm values are relatively more likely after a low state of nature (due to the fact that $G_{\theta}(s)$ satisfies MLRP), the bonus scheme described in Proposition 2 minimizes the CEO's expected on-the-job compensation in low states of nature. This makes it as unattractive as possible for the $\mathrm{CEO}$ to continue in these states, which implies less severance pay will be needed to induce him not to entrench himself. Formally, the bonus scheme described in Proposition 2 minimizes $E[w(s) \mid \theta]$ at low values of $\theta$, thus implementing a given cutoff $\theta^{*}$ with the minimum possible amount of severance pay.

Given that the CEO earns a rent (in dollar terms) equal to $W$, and given that the interval $\left[\theta^{*}, \theta_{F B}\right)$ represents the CEO's entrenchment region, we can state Proposition 2 alternatively as follows: A high-powered bonus scheme minimizes the CEO's rents while allowing a given level of entrenchment, or equivalently, it minimizes the CEO's entrenchment while leaving him a given amount of rents.

The flip side of shifting all of the CEO's compensation into states where the firm's value is highest is that the bonus scheme described in Proposition 2 provides the CEO with a relatively high expected compensation in high states of nature. This is inconsequential, however, as in high states of nature it is indeed optimal to retain the CEO. 


\subsection{Discussion and Further Analysis}

To the best of our knowledge, our argument that shifting the CEO's entire compensation into states where the firm's value is highest makes the board's replacement decision more efficient is novel. However, we are not the first model in which it is optimal to shift an agent's entire payoff into extreme states of nature. In Innes' (1990) moral hazard model, for instance, it is optimal to shift the entrepreneur's entire payoff into high cash-flow states as these are most informative about his effort. In both our model and Innes' model-like in other related models where it is optimal to shift an agent's entire payoff into extreme states of nature (e.g., Nachman and Noe (1994)) - the result hinges on an assumption that the underlying probability distribution satisfies a particular monotonic ordering. ${ }^{21}$

Absent any further constraints, the fact that the CEO's entire compensation should be shifted into states where the firm's value is highest implies that his optimal compensation scheme will take an extreme form: it makes the CEO the full claimant to the firm's value above a certain threshold (denoted by $\hat{s}$ in Proposition 2). ${ }^{22}$ Such a discontinuous compensation scheme may entail problems of its own, however. For instance, if the firm's value in $t=2$ increases only slightly from $\hat{s}-\varepsilon$ to $\hat{s}$, the CEO's compensation jumps from zero to $w(s)=\hat{s}$, which in turn may tempt the CEO to manipulate the firm's value upwards. To examine the implications of this problem for the optimal compensation scheme, suppose the CEO retires in $t=2$ while the firm is long-lived. We shall now depart from our previous setup and assume the CEO can manipulate the firm's value in $t=2$. Manipulation comes at a private cost $h(\Delta)$, where $\Delta=\left|s^{\prime}-s\right|$ and where $s^{\prime}$ denotes the manipulated firm value and $s$ denotes the true value. The cost function $h(\Delta)$ is nondecreasing and convex with $h(0)=0$ and $h^{\prime}(0)=\gamma$, where $\gamma$ is positive but small. ${ }^{23}$

\footnotetext{
${ }^{21}$ Both Innes (1990) and this paper assume that the probability distribution satisfies MLRP. Other monotonic orderings sometimes used in the literature are conditional stochastic dominance (e.g., Nachman and Noe (1994)) or, closely related, the monotone hazard rate property.

${ }^{22}$ The only binding constraint we have hitherto imposed on the CEO's on-the-job compensation scheme is $w(s) \leq s$. As noted previously, the constraint that $w(s)$ be nondecreasing was only introduced to simplify the analysis. Given that the optimal solution requires to shift as much as possible of the CEO's compensation into states where $s$ is highest, it is easy to see that this constraint does not bind at the optimum.

${ }^{23}$ The CEO's private cost of manipulating the firm's value by $\Delta$ might realistically be less than $\Delta$-at least for small $\Delta$-implying that $\gamma \leq 1$. The special case where $\gamma=1$ coincides with an assumption frequently made in the financial contracting literature that $s-w(s)$ be nondecreasing (e.g., Innes (1990), Nachman and Noe (1994), DeMarzo and Duffie (1999)). The argument commonly used to justify this assumption is that otherwise the firm's
} 
Manipulation may be costly for the CEO either because it requires additional effort or because the $\mathrm{CEO}$ faces negative consequences if the manipulation is detected.

We restrict consideration to optimal on-the-job compensation schemes ensuring that no manipulation takes place in equilibrium. Since $h(\Delta)$ is nondecreasing and convex, any compensation scheme ruling out "small" manipulations around $\Delta=0$ automatically also rules out "large" manipulations $\Delta>0$, which implies the binding constraint on the CEO's optimal compensation scheme derives from the derivative of $h(\Delta)$ at $\Delta=0 .{ }^{24}$

The fact that the CEO can manipulate the firm's value in $t=2$ introduces an additional constraint on his optimal on-the-job compensation scheme, namely, that the CEO's marginal manipulation cost at $\Delta=0$ must equal or exceed his marginal benefit from manipulating for all $s \in S$. Since the CEO's optimal on-the-job compensation scheme requires to shift as much as possible of his compensation into states where the firm's value is highest, this additional constraint is binding. We then have the following result.

Proposition 3. Suppose the CEO can manipulate the firm's value in $t=2$ at marginal cost greater than or equal to $\gamma>0$. Then the uniquely optimal CEO compensation package consists of severance pay and some on-the-job compensation scheme paying $w(s)=0$ if $s<\hat{s}$ and $w(s)=\gamma(s-\hat{s})$ if $s \geq \hat{s}$ for some $\hat{s} \in(\underline{s}, \bar{s})$.

Proof. See Appendix.

While it is still true that the CEO's optimal on-the-job compensation scheme must shift as much as possible of his compensation into states where the firm's value is highest, there is now an additional binding constraint that renders the discontinuous bonus scheme proposed in Proposition 2 infeasible. Arguably, the compensation scheme proposed in Proposition 3 is less extreme than that proposed in Proposition 2. Instead of making the CEO the full claimant to the firm's value above some threshold, the CEO now only receives a fraction $\gamma$ of the firm's incremental value above some threshold. This compensation scheme can be implemented by

shareholders might have an incentive to destroy firm value.

\footnotetext{
${ }^{24}$ If a "small" manipulation from $s$ to $s^{\prime}=s+\varepsilon$ is ruled out, then any "large" manipulation from $s^{\prime \prime}<<s$ to $s^{\prime}$ is also ruled out as the manipulation cost for the last increment from $s$ to $s^{\prime}$ is weakly greater under the large manipulation due to the fact that $h^{\prime}(\Delta)$ is nondecreasing. An analogous argument holds for $s^{\prime}=s-\varepsilon$.
} 
giving the CEO stock options. ${ }^{25}$ In what follows, we will continue with the optimal compensation scheme derived in Proposition 3.

Realistically, the CEO's manipulation technology will depend on the firm's corporate governance, which is endogenous, but also on its legal and regulatory environment. It is therefore of interest to consider the effect of an exogenous shift in the CEO's manipulation cost. The following result is immediate given Proposition 3 and our preceding discussion.

Proposition 4. As the CEO's marginal manipulation cost $\gamma$ increases, his optimal on-the-job compensation scheme becomes "steeper"-i.e., the pay-for-performance sensitivity increasesand it becomes less costly to reduce the CEO's entrenchment.

Proof. See Appendix.

The robust insight from our analysis is that the CEO's optimal compensation scheme should shift as much as possible of his compensation into states where the firm's value is highest. How much precisely "as much as possible" is will depend on the constraints imposed on the model. In a relatively unconstrained setting like that in Section 3.2, the optimal compensation scheme is a high-powered, discontinuous bonus scheme. If we introduce a simple manipulation problem like in this section, the optimal compensation scheme becomes a stock option. There are many other possible constraints that one might want to consider, although some are more difficult to incorporate in our model than others. For instance, to obtain a closed-form solution we must assume that the CEO is risk neutral. While this assumption is restrictive, it might be less of a problem for CEOs who are potentially less risk averse than ordinary employees due to their high wealth. A simple, yet arguably crude way of capturing some basic aspects of risk aversion would be to introduce a minimum consumption requirement $w(s) \geq C$. With this additional constraint, the optimal compensation scheme in Proposition 3 changes only insofar as the CEO now receives a base wage equal to $C$ in addition to stock options.

\footnotetext{
${ }^{25}$ The option's "strike price" $\hat{s}$ is uniquely pinned down by the requirement that (4) binds. For the sake of brevity, Proposition 3 does not include the case where $\gamma$ is sufficiently close to zero so that (4) cannot be satisfied for any $\hat{s}>\underline{s}$. As $\gamma$ approaches zero, the option's "strike price" $\hat{s}$ goes to $\underline{s}$ and the CEO's optimal on-the-job compensation scheme becomes $w(s)=F+\gamma s$, which can be implemented by giving the CEO a fixed wage of $F$ plus stock.
} 


\subsection{Severance Pay and Entrenchment}

From Section 4.2 we know that the optimal CEO compensation scheme minimizes his severance pay (and hence his informational rents) $W$ while holding the cutoff $\theta^{*}$ fixed, or equivalently, it maximizes $\theta^{*}$ while holding $W$ fixed. We shall now explore the implications of a change in $W$ on $\theta^{*}$. Intuitively, as $W$ increases it becomes relatively less attractive for the CEO to continue. At the same time, however, the increase in $W$ must be matched by a simultaneous increase in the CEO's expected on-the-job compensation to preserve the wedge required by (4), which makes it relatively more attractive for the CEO to continue. As we will show, under the optimal CEO compensation scheme the first effect outweighs the second, implying the overall effect of an increase in $W$ is that it increases $\theta^{*}$, thus reducing the CEO's entrenchment.

Under the optimal compensation scheme derived in Proposition 3 (or Proposition 2 for that matter), the increase in the CEO's on-the-job compensation that is necessary to match the increase in $W$ will occur at relatively high values of $s$, implying the CEO's expected on-thejob compensation $E[w(s) \mid \theta]$ increases primarily in high states of nature. Conversely, in low states of nature $E[w(s) \mid \theta]$ increases only little. Hence, while on average the CEO's expected on-the-job compensation must increase one-for-one with his severance pay (cf., (6)), it increases by more than $W$ in high and by less than $W$ in low states of nature. Consequently, in low states of nature the difference $E[w(s) \mid \theta]-W$ decreases, implying it is possible to push up $\theta^{*}$ by increasing $W$, thus reducing the CEO's entrenchment (at the cost of leaving him more rents).

Proposition 5. Under the optimal CEO compensation scheme the board can reduce the CEO's entrenchment by increasing his severance pay. This is despite the fact that an increase in the CEO's severance pay must be matched by a simultaneous increase in his expected on-the-job compensation to preserve his incentives to work hard. Fully eliminating the CEO's entrenchment is too costly, however: at the optimal solution it holds that $\theta^{*}<\theta_{F B}$.

Proof. See Appendix.

Proposition 5 illustrates the interplay between the CEO's on-the-job compensation and his severance pay. While an increase in either one of these two variables improves the CEO's expected payoff, they are not substitutes. Instead, the CEO's severance pay and his on-thejob compensation must move in the same direction. ${ }^{26}$ This has important implications. For

\footnotetext{
${ }^{26}$ While the optimal value of $W$ trades off the benefits of reducing the CEO's entrenchment against the costs of
} 
instance, if the board faces pressure to cut the CEO's severance pay, it cannot compensate him for the loss by simultaneously raising his on-the-job compensation, and vice versa. ${ }^{27}$ Tilting the delicate balance between the CEO's severance pay and his on-the-job compensation in one direction or another only creates adverse incentive effects - either for the CEO's incentives to work hard or his incentives to entrench himself.

Proposition 5 also shows that it is never optimal to set $\theta^{*}=\theta_{F B}$. Since increasing $\theta^{*}$ is costly, it is, of course, also never optimal to set $\theta^{*}>\theta_{F B}$, implying at the optimum it holds that $\theta^{*}<\theta_{F B}$. The reason is that, by standard arguments, a marginal change in $\theta^{*}$ at $\theta^{*}=\theta_{F B}$ has a negligible effect on shareholders' expected payoff. A marginal reduction in the CEO's rents, however, constitutes a first-order cost saving for shareholders.

Both academics and shareholder activists have recently put the spotlight on what they contend are excessive severance packages for top executives. A commonly found argument is that severance pay constitutes a "reward" for failure, which is not only unnecessary but also counterproductive as it reduces CEOs' incentives to work hard. ${ }^{28}$ Indeed, this is precisely what would also happen in our model if the CEO's severance pay were set too high relative to his onthe-job compensation. However, as granting the CEO severance pay is necessary to induce him to give up his entrenchment, our analysis cautions that any unduly cut in the CEO's severance pay may come at a high cost: while it arguably curtails the CEO's rents, it weakens his incentives to give up his entrenchment. The following result is immediate given our previous analysis.

leaving him more rents, the specific solution depends on the distributional assumptions. Once $W$ is pinned down, however, the remaining choice vvariable $\hat{s}$ (and therefore also $\theta^{*}$ ) is uniquely pinned down by the requirement that (4) binds.

${ }^{27}$ This suggests that severance pay is not merely a form of "stealth compensation" (cf., Bebchuk and Fried (2004)) that can be adjusted to offset cuts in executives' on-the-job compensation.

${ }^{28}$ The U.S. has recently witnessed an abundance of such cases. A prominent example is the lawsuit by Walt Disney shareholders against the company for awarding Michael Ovitz severance pay worth $\$ 140$ million after being only 14 months with the firm. But public pressure against severance pay is not limited to the U.S. The U.K., for instance, recently had a public inquiry about "rewards for failure" (DTI (2003)), and it has witnessed a substantial amount of shareholder activity against high severance pay. As a result, listing rules were amended in 2002 to require firms to publish their directors' remuneration reports, which must be approved by shareholders. While this approval is only advisory, the vote helped shareholder activists to gain publicity in their fight against high severance packages, for instance in the case of the advertising company WPP, the retailing chain Sainsbury's, and perhaps most prominently, in the case of rejecting a £20 million contractually stipulated severance package for the head of GlaxoSmithKline, Britain's biggest drug manufacturer. 
Proposition 6. Introducing a binding cap on the CEO's severance pay is inefficient. While it reduces the CEO's rents, it weakens his incentives to give up his entrenchment and reduces overall shareholder value.

\subsection{General Compensation Schemes}

Thus far we have assumed that the CEO's compensation package takes the simple form where $W$ is a constant and where $w(s)$ depends only on the firm's value in $t=2$. Given that the state of nature is a continuous variable, one might wonder if the board can possibly do better by tying the CEO's compensation even closer to the underlying state of nature. We will now show that this is not the case.

A more general mechanism would specify that the CEO - after observing the state of naturecan choose from a prespecified menu of compensation packages. The corresponding direct mechanism would specify for every (announced) state of nature $\theta \in \Theta$ i) the board's action whether or not to replace the CEO, and ii) severance pay $W(\theta)$ if the CEO is replaced and some on-thejob compensation scheme $w(s, \theta)$ if he is retained. Note that both $w$ and $W$ may now depend nontrivially on $\theta$. Denote the set of states in which the CEO is replaced by $\Theta_{-}$and the set of states in which he is retained by $\Theta_{+}=\Theta / \Theta_{-}$.

It is straightforward to see that it cannot be optimal to have different levels of severance pay in different states of nature $\theta \in \Theta_{-}$. This is because conditional on announcing some state of nature in the set $\Theta_{-}$, the CEO would always announce the state that yields him the highest severance pay. That is, he would always announce $\theta \in \arg \max _{\theta^{\prime} \in \Theta_{-}} W\left(\theta^{\prime}\right)$. The CEO's severance pay must consequently be a constant $W(\theta)=W$.

There is a similarly straightforward argument why introducing a menu of on-the-job compensation schemes $w(s, \theta)$ is not helpful. Since the board's decision is binary, all it needs to know is whether $\theta$ is an element of $\Theta_{-}$or $\Theta_{+}$. Neither in the case where the CEO is replaced nor in the case where he is retained does the board gain anything by having more detailed information. Hence, there is no obvious reason to let the CEO choose from a menu that reveals more about the underlying state of nature. In what follows, we will prove an even stronger result that a menu of on-the-job compensation schemes is strictly suboptimal. The uniquely optimal solution is thus to offer the CEO the uniquely optimal "single" on-the-job compensation scheme $w(s, \theta)=w(s)$ derived previously. 
The intuition is as follows. The optimal CEO on-the-job compensation scheme derived previously shifts more of his compensation into states where the firm's value is highest - thus shifting more of his expected on-the-job compensation $E[w \mid \theta]$ into high states of nature - than any other feasible on-the-job compensation scheme. By construction, any richer menu of compensation schemes $w(\theta, s)$-regardless of whether or not it includes the "single" optimal compensation scheme - must therefore shift some of the CEO's expected compensation "back" into low states of nature. ${ }^{29}$ That is, a richer menu of compensation schemes does not minimize $E[w \mid \theta]$ when $\theta$ is low. But this property of minimizing the CEO's expected on-the-job compensation in low states of nature is precisely what drives optimality in our model, as it allows the board to minimize the CEO's entrenchment at the lowest cost to shareholders. With a richer menu $w(\theta, s)$ the board would thus either have to leave the CEO more informational rents to implement the same cutoff $\theta^{*}$, or - if the board wants to hold the CEO's rents fixed-tolerate a lower cutoff and hence more CEO entrenchment.

Proposition 7. Even though the CEO has private information with respect to a continuous variable $\theta$, it is uniquely optimal to offer him a simple compensation package consisting of a single on-the-job compensation scheme $w(s)$ and a fixed severance payment $W$.

Proof. See Appendix.

\subsection{An Alternative View of Entrenchment}

Our base model assumes that the CEO can entrench himself by hiding negative information that would allow the board to conclude that his match quality is poor. In what follows, we show that our model is also compatible with a different (somewhat more conventional) notion of entrenchment where the CEO makes an irreversible "protective" investment that makes it suboptimal for the board to replace him (e.g., Shleifer and Vishny (1989), Scharfstein and Stein (2000)). In contrast to our base model, let us now assume that the board can perfectly observe $\theta$ in $t=1$. The CEO, however, learns $\theta$ before the board does. Moreover, while both the CEO and the board know $\theta$ in $t=1$, we assume $\theta$ it is nonverifiable. If $\theta$ were verifiable, the board

\footnotetext{
${ }^{29}$ As this line of reasoning suggests, the argument that a menu of compensation schemes is suboptimal holds regardless of whether we impose additional constraints on the optimal compensation scheme, as in Proposition 3 , or whether we consider a relatively unconstrained setting like that in Proposition 2.
} 
could contractually commit to a decision rule based on $\theta$ ex ante - even if this rule was ex-post suboptimal - in which case any protective actions taken by the CEO would be meaningless.

For concreteness, suppose after observing $\theta$ the CEO can take a protective action that makes it harder for a potential successor to take over his job, thus reducing the value of the board's option to replace him, which is denoted by $V$ in our model. ${ }^{30}$ Without loss of generality, we may assume the CEO can directly control $V{ }^{31}$ Denote the CEO's choice of $V$ by $\hat{V}$. Like in Shleifer and Vishny (1989) and Scharfstein and Stein (2000), it is important that the CEO takes the protective action before meeting with the board. Simply threatening the board to take the action will not suffice: the board would fire the CEO on the spot, thus preventing him from changing $V$. Finally, note that the CEO's action does not affect the firm's value if he remains in power; it only affects the value of replacing him.

Given these assumptions, it is easy to see that this model is fully isomorphic to our base model in which only the CEO knows $\theta$ in $t=1$. By our previous arguments, the CEO wants to continue if and only if $\theta \geq \theta^{*}$, where $\theta^{*}$ is given by $E\left[w(s) \mid \theta^{*}\right]=W$. The board, on the other hand (knowing $\theta$ ) will retain the CEO in $t=1$ if and only if

$$
E[s-w(s) \mid \theta] \geq \hat{V}-W
$$

Since the left-hand is positive, the CEO can always assure his retention by setting $\hat{V}$ sufficiently low. Like in our base model, the CEO thus has effective control over the board's decision. In consequence, the board's problem in $t=0$ is identical to that in our base model, which implies our previous results extend qualitatively to this alternative notion of entrenchment.

\footnotetext{
${ }^{30}$ Scharfstein and Stein (2000) give the example of a manager who creates an opaque accounting system that it difficult to understand for a potential successor. Relatedly, the CEO can hide or obscure information that a successor needs to successfully run the firm. For more examples, see Shleifer and Vishny (1989).

${ }^{31}$ The model is fully isomorphic to our base model only if the CEO can change $V$ at no cost. While examples of how the CEO can reduce $V$ are relatively easy to come by, arguing that the CEO can increase $V$ may be more difficult. In the end, this is not a concern. Assuming that the CEO can freely change $V$ up- or downwards, only the latter will impose a binding constraint in equilibrium, just like in our base model where the CEO may hide bad but not good information in equilibrium
} 


\section{Comparative Statics Analysis}

\subsection{CEO Pay and Business Environment}

To induce the CEO to make room for value-increasing changes in the firm's strategy and management, shareholders must leave him valuable rents. Given that reducing the CEO's entrenchment is costly, the question is how much entrenchment should the firm's shareholders optimally tolerate? In this section we argue that the answer may depend on the firm's business environment. In a stable environment where the ex-ante likelihood that a change in the firm's strategy and management becomes optimal in the future is relatively small, the cost of having an entrenched CEO is also relatively small. Conversely, in a less stable environment where this ex-ante likelihood is large, the cost of having an entrenched CEO is potentially severe.

In our model, the ex-ante likelihood that a change in the firm's strategy and management becomes optimal in the future is $F\left(\theta_{F B}\right)$. As $\theta_{F B}$ increases, there are more states of nature in which maintaining the status quo is inefficient. In consequence, the board must raise the second-best cutoff $\theta^{*}$ to ensure that the status quo is indeed maintained less often. From our previous analysis, however, we know that raising $\theta^{*}$ is costly. It implies the board must increase both the CEO's severance pay and - to preserve the wedge required by (4) - also his on-the-job compensation. Accordingly, we have that CEOs in less stable business environments should receive both higher severance pay and higher on-the-job compensation. At the same time, the fact that $\theta^{*}$ is higher also implies that it becomes more likely that the CEO will be replaced, i.e., CEO turnover should be higher as well.

In what follows, we assume that the board's objective function is strictly quasiconcave in $W$. This ensures the existence of a uniquely optimal choice of $W$, and consequently also of $\theta^{*}$ and $w(s)$. (Once $W$ is pinned down, the remaining choice variables $\theta^{*}$ and $w(s)$ are uniquely determined by our model.) We have the following result.

Proposition 8. As the firm's business environment becomes more unstable-implying it is more likely that a change in the firm's strategy and management becomes optimal in the futurethe board increases both the CEO's severance pay and his on-the-job compensation, while the likelihood that the CEO is replaced in the future increases correspondingly.

Proof. See Appendix. 
Proposition 8 shows that it can be optimal to pay CEOs potentially generous compensation packages if the firm's business environment is relatively unstable. ${ }^{32}$ This reduces the CEO's incentives to entrench himself in precisely those situations where flexibility and the ability to adapt to changes in the firm's environment are key.

With the usual degree of caution, we may try to link Proposition 8 to some developments taking place since the late 1970s. Like Jensen (1993) and many others, Holmström and Kaplan (2001) have argued that the "pace of economic change has accelerated" since the late 1970s. Between 1978 and 1996, some of the most important industries in the U.S., including airlines, broadcasting, entertainment, natural gas, trucking, banks and thrifts, utilities, and telecommunications, have experienced massive deregulations (Andrade, Mitchell, and Stafford (2001)). The 1980s and 1990s also witnessed fundamental technological innovations, notably in the information technology and telecommunications sectors, that have radically altered the industrial landscape in the U.S. These developments - key forces behind what Jensen (1993) calls "Modern Industrial Revolution" - have put increasing pressure on U.S. firms to change their business strategies, industry focus, and managements. The takeover and merger waves of the 1980s and 1990s are frequently viewed as consequences of these developments.

Proposition 8 suggests that the increasing need to remain flexible comes at a potentially high cost: CEO compensation, both in terms of severance pay and on-the-job compensation, must increase correspondingly. This is consistent with the surge in CEO stock option grants over the past decades documented by Hall and Liebman (1998). Accordingly, the mean value of CEO stock option grants has increased almost sevenfold between 1980 and 1994, from about \$155,000 to over $\$ 1,210,000$. Similarly, Bebchuk and Grinstein (2005) show that between 1993 and 2003 the average CEO compensation among S\&P 500 firms (measured in 2002 dollars) has increased almost threefold from $\$ 3.7$ million to $\$ 9.1$ million. ${ }^{33}$ Finally, Huson, Parrino, and Starks (2001) argue that - concurrent with the rise in CEO compensation - CEO turnover has also increased over the past decades.

\footnotetext{
${ }^{32}$ An increase in uncertainty - e.g., in the form of a mean-preserving spread - does not necessarily imply that it becomes more likely that a change in the firm's strategy and management becomes optimal in the future. What is important is that $\theta_{F B}$ increases.

${ }^{33}$ As for severance pay, Walker (2005) argues that there has been a surge in (contractually stipulated) severance pay, while Lefanowicz, Robinson, and Smith (2000) and Bebchuk, Cohen, and Ferrell (2004) find that the use of golden parachutes has increased substantially in the 1980s and 1990s.
} 
The recent surge in CEO compensation is also the subject of several related papers. Like this paper, Dow and Raposo (2005) also link this trend to the fact that firms' business environments have become more unstable. In their model, this means CEOs must get higher pay because the range of possible alternative business strategies - in particular strategies involving radical changes - has increased, and shareholders must incentivize CEOs not to pursue such radical strategies. ${ }^{34}$ Bebchuk and Fried's (2004) "managerial power perspective" has a substantially different flavor. They argue that the rising stock market of the 1990s gave executives and boards more latitude to boost executive pay. In their view, boards do not maximize shareholder value. Murphy and Zábojník (2004), in contrast, argue that the surge in CEO compensation reflects a fundamental shift in the relative importance of general versus firm-specific human capital. Beneficiaries are CEOs with above-average general human capital, whose compensation is being bid up by the market. Finally, both Almazan and Suarez (2003) and Hermalin (2003) link the rise in CEO compensation to changes in corporate governance. In Almazan and Suarez' model a shift from weak to strong boards is accompanied by a greater use of incentive pay and more turnover. Hermalin, on the other hand, argues that the rise in CEO compensation reflects greater board diligence. To compensate CEOs for the increased likelihood of being fired, their pay must increase.

Proposition 8 might also lend itself for some cross-sectional implications. Accordingly, industries witnessing fundamental changes should exhibit higher CEO turnover but also higher CEO compensation. ${ }^{35}$ We are not aware of empirical studies analyzing how CEO pay and turnover depend on industry characteristics. ${ }^{36}$

Institutional investors in many countries have recently turned against large CEO compensation packages, mainly in response to public pressure. While Proposition 8 implies that high CEO compensation may be warranted under some circumstances, it does not say that high CEO

\footnotetext{
${ }^{34}$ In some sense, the problem is the opposite of ours where CEOs must be incentivized not to block changes.

${ }^{35}$ In fact, one of the implications of our model is that the increase in CEO severance pay and on-the-job compensation more than compensates CEOs for an increase in the turnover likelihood. Hence, despite a potentially higher turnover rate, CEO positions in unstable industries should remain attractive.

${ }^{36}$ See Daines, Nair, and Kornhauser (2005) for some descriptive statistics, however. Also, there is some evidence that CEO pay is lower in regulated industries which - one could argue - are relatively more stable (see Murphy (1999) for an overview of the literature). Similarly, Crawford, Ezzell, and Miles (1995) and Hubbard and Palia (1995) both find that deregulation seems to have contributed to the rise of CEO pay in the banking industry.
} 
compensation is unequivocally desirable. For instance, if the CEO's on-the-job compensation is too large relative to his severance pay, any unduly increase in his on-the-job compensation only aggravates his entrenchment problem. Our model does, however, suggest that imposing an artificial cap on the CEO's compensation may easily backfire (see also Proposition 6). The consequence may be more, not less CEO entrenchment, less flexibility, and lower shareholder value.

\subsection{CEO Pay and Firm Characteristics}

\section{CEO Pay and Firm Size}

Our analysis makes a natural prediction concerning the relation between CEO pay and firm size. Intuitively, at larger firms there is more at stake: for a given state of nature $\theta<\theta_{F B}$ it is more costly for largers firms if the CEO stays in power when he should be replaced. To mitigate these higher costs, larger firms should therefore have a higher $\theta^{*}$ and hence higher CEO turnover. Moreover, from our previous analysis we know that implementing a higher $\theta^{*}$ is costly: it implies that larger firms must offer their CEOs both higher severance pay and higher on-the-job compensation. To explore the implications of firm size for CEO pay and turnover, we have scaled up both $V$ and $s$ by a factor $\alpha>0$. We have the following result.

Proposition 9. CEOs of larger firms should receive both higher severance pay and higher on-the-job compensation. At the same time, larger firms should have higher CEO turnover.

Proof. See Appendix.

While varying firm size, we have not adjusted the CEO's private benefits $B$ of shirking. This is because it seems not obvious to us if CEOs of larger firms need to work more or less hard. Finally, it goes without saying that there may be alternative reasons for why CEOs of larger firms are paid more, e.g., larger firms may need more talented and hence more expensive CEOs. It is not clear, though, why this argument should necessarily also imply that larger firms have higher CEO turnover. ${ }^{37}$

\footnotetext{
${ }^{37}$ Conyon (1997) and Bebchuk and Grinstein (2005) both find that CEO compensation increases with firm size. For evidence that larger firms have higher executive turnover, see Warner, Watts, and Wruck (1988) and Murphy (1999). Again, we do not mean to argue that there exists no plausible alternative explanation for this fact. For instance, in smaller firms the CEO may often be the firm's founder, who naturally remains longer in his position.
} 


\section{CEO Pay and Firm Governance}

There are two "drivers" in our model that affect the size of the CEO's compensation. First, the CEO must be compensated for forgoing his private benefits $B$. Second, he must be compensated for not becoming entrenched, which secures him an additional rent of $W$ on top of being compensated for his private benefits. In the following, we examine how these two factors interact.

Suppose $B$ increases. The direct effect of this increase is that the CEO's on-the-job compensation must increase correspondingly to ensure that he does not shirk. But this only strenghtens the CEO's incentives to remain in power after observing a low state of nature, i.e., the CEO's privately optimal cutoff $\theta^{*}$ goes down. To counteract this drop in $\theta^{*}$, the board must raise the CEO's severance pay, which — as we have shown previously - must be accompanied by an (additional) increase in his on-the-job compensation. As Proposition 10 below shows, however, it is not optimal to push $\theta^{*}$ all the way up back to its original level. In consequence, an increase in $B$ results in a lower cutoff $\theta^{*}$ and hence in a higher level of CEO entrenchment.

The extent to which the CEO can consume private benefits may depend on his particular job. Some CEO jobs may arguably allow for more perk consumption than others. But it will realistically also depend on the firm's corporate governance, which imposes a natural limit on how much perks the CEO can consume. In this regard, $B$ will be inversely related to the quality of the firm's corporate governance, if we define the latter with respect to the ease with which CEOs can appropriate private benefits. ${ }^{38}$ We then have the following result.

Proposition 10. In firms with weak corporate governance it is more costly to reduce CEO entrenchment in the sense that CEOs must be granted higher severance pay-and hence more rents - as well as a higher on-the-job compensation. Moreover, firms with weak corporate governance will have more entrenched CEOs.

Proof. See Appendix.

Broadly speaking, Proposition 10 appears to be consistent with the empirical evidence, although one must be cautious when equating explanatory variables used in empirical studies with

\footnotetext{
${ }^{38}$ This is arguably a narrow definition of corporate governance. Note that there is no contradiction in assuming that the board can limit the CEO's consumption of private benefits and assuming that the CEO has better information about his match-specific quality or the likely success of the firm's current strategy.
} 
"corporate governance quality", which is a broad and relatively vague term. Generally, however, it seems that CEO turnover is higher in firms with stronger corporate governance, and weak corporate governance seems to be conducive to higher CEO pay. ${ }^{39}$

\section{Conclusion}

An important question in the debate about corporate governance is how the effectiveness of boards can be improved. Most efforts along these lines have focused on changing the board itself-i.e., its size and structure and the incentives given to individual board members. But there is no reason why such efforts should be limited to the board in a narrow sense. In the end, any instrument or institution that can help mitigate the information disparity between the CEO and the board will also make the board a better monitor. In this paper, we focus on an instrument that, like the board of directors, has received much attention lately: executive compensation. Specifically, assuming that the board cannot fully overcome the information asymmetry vis-à-vis the CEO, we ask if there is a role for executive compensation in mitigating the remaining inefficiency.

Our focus is on the board's decision to replace the CEO. Given the CEO's control over the board's information, he can easily entrench himself by simply hiding negative information that would otherwise lead to his replacement. In the face of this problem, we find that it is optimal to give the CEO a high-powered, non-linear compensation scheme that shifts as much as possible of his compensation into states where the firm's value is highest. Prominent examples are bonus schemes and stock options. Intuitively, under a high-powered bonus scheme or option grant the CEO's incentives to entrench himself are minimized if he expects that the firm's future value under his continuing leadership is low. In consequence, less severance pay will be needed to induce the CEO not to entrench himself in these situations. In our model, severance pay is a measure of the CEO's informational rents. Hence, we find that a high-powered, non-linear compensation scheme minimizes the CEO's informational rents while allowing a given level of CEO entrenchment. Or, equivalently, it minimizes the CEO's entrenchment while leaving him a given amount of rents.

While our model suggests that generous CEO compensation packages may be warranted

\footnotetext{
${ }^{39}$ For empirical evidence see, e.g., Core, Holthausen, and Larcker (1999), Cyert, Kang, and Kumar (2002), and the literature surveyed in Hermalin and Weisbach (2003).
} 
under certain circumstances, it does not give a carte blanche to high CEO compensation as such. A generous compensation package is only effective if the board can strike the right balance between the CEO's on-the-job compensation and his severance pay. If the CEO's on-the-job compensation is too large, he will never be willing to give up his power. Conversely, if the CEO's severance package is too large, he will shirk and inefficiently focus on his exit options. Finally, given that the CEO must be granted a potentially generous compensation package, it is not optimal to fully eliminate CEO entrenchment, but only to mitigate it.

On a broader scale, our results suggest that formal or informal restrictions on either the level or composition of CEO pay may stifle economic change. Promoting flexibility and voluntary exit may require granting CEOs substantial rents in the form of seemingly generous severance packages. In turn, high-powered compensation packages are necessary to economize on severance pay and thus ultimately on the rents that CEOs can appropriate. Countries in which formal or informal restrictions on CEO pay practices exist may therefore experience more, not less, CEO entrenchment and may undergo less industrial change.

\section{Appendix}

Proof of Proposition 2. The fact that $W>0$ follows from the argument in the main text. It remains to prove that it is uniquely optimal to give the CEO an on-the-job compensation scheme of the form $w(s)=0$ if $s<\hat{s}$ and $w(s)=s$ if $s \geq \hat{s}$ for some $\hat{s} \in(\underline{s}, \bar{s})$.

We argue to a contradiction. Suppose thus that the board wants to implement some $\theta^{*}$ with a different on-the-job pay scheme $\widetilde{w}(s)$. We denote the corresponding severance pay by $\widetilde{W}$. We show that there exists some $w(s)$ such that (i) the constraint (4) remains binding and that (ii) $\theta^{*}$ is still implemented - though now with a lower severance pay $W$. That is, with a slight abuse of notation the new compensation scheme satisfies $\theta^{*}(w, W)=\theta^{*}(\widetilde{w}, \widetilde{W})=\theta^{*}$ and $W<\widetilde{W}$, which by inspection of (2) would contradict optimality of the original contract $\widetilde{w}(s)$.

We proceed in two steps. We first choose $\bar{W}=\widetilde{W}$ and $\bar{w}(s)$ with $\bar{w}(s)=0$ for $s<\widehat{s}$ and $\bar{w}(s)=s$ for $s \geq \widehat{s}^{\prime}$ such that $\theta^{*}(\bar{w}, \bar{W})=\theta^{*}$. That is, with $d(s):=\widetilde{w}(s)-\bar{w}(s)$ we have that

$$
\int_{S} d(s) g_{\theta^{*}}(s) d s=0
$$

Given the construction of $\bar{w}(s)$, which pays nothing for low and all for high $s$, there must be a value $\widetilde{s} \in(\underline{s}, \bar{s})$ such that $d(s) \geq 0$ for all $s<\widetilde{s}$ and $d(s) \leq 0$ for all $s>\widetilde{s}$, where both inequalities 
are strict over sets of positive measure. Take now any $\widehat{\theta}>\theta^{*}$. By MLRP of $G_{\theta}(s)$ and (8), it then holds that

$$
\begin{aligned}
\int_{S} d(s) g_{\widehat{\theta}}(s) d s & =\int_{\underline{s}}^{\widetilde{s}} d(s) g_{\theta^{*}}(s) \frac{g_{\widehat{\theta}}(s)}{g_{\theta^{*}}(s)} d s+\int_{\widetilde{s}}^{\bar{s}} d(s) g_{\theta^{*}}(s) \frac{g_{\widehat{\theta}}(s)}{g_{\theta^{*}}(s)} d s \\
& <\frac{g_{\widehat{\theta}}(\widetilde{s})}{g_{\theta^{*}}(\widetilde{s})} \int_{S} d(s) g_{\theta^{*}}(s) d s=0,
\end{aligned}
$$

which implies that the constraint (4) is slack if we choose $\bar{w}(x)$ and $\bar{W}$.

In a second step, we can now construct the asserted compensation scheme with $w(s)=0$ for $s<\widehat{s}$ and $w(s)=s$ for $s \geq \widehat{s}$ and with $W<\bar{W}=\widetilde{W}$. For this we continuously increase the threshold $\widehat{s}^{\prime}$ in $\bar{w}(s)$ and decrease $\bar{W}$, while still satisfying $\theta^{*}(\bar{w}, \bar{W})=\theta^{*}$, until (4) becomes again binding. That this is possible follows from continuity of payoffs in $\hat{s}^{\prime}$, while (4) surely does not hold as we approach the upper limit with $\widehat{s}^{\prime} \rightarrow \bar{s}$ (and thus from $\theta^{*}(\bar{w}, \bar{W})=\theta^{*}$ also $\bar{W} \rightarrow 0)$. This completes the proof of Proposition 2. Q.E.D.

Proof of Proposition 3. By the argument in the main text the possibility of manipulation adds one additional constraint to the firm's program: that the slope of $w(s)$ must not exceed $\gamma$. (Note that $w(s)$ is then necessarily continuous such that by monotonicity it is almost everywhere differentiable.) Following the argument in footnote 25, we restrict consideration to $\gamma \leq 1$. We argue again to a contradiction and suppose that the firm wants to implement a given $\theta^{*}$ with another contract $\widetilde{w}(s)$. As in the proof of Proposition 2, we can then again construct a contract $\bar{w}(s)$ with $\bar{w}(s)=0$ for $s<\hat{s}^{\prime}$ and $\bar{w}(s)=\gamma(s-s)$ for $s \geq \hat{s}^{\prime}$ such that (8) is satisfied. As also the slope of $\widetilde{w}(s)$ must not exceed $\gamma$, there exists again a value $\widetilde{s} \in(\underline{s}, \bar{s})$ such that $d(s) \geq 0$ for all $s<\widetilde{s}$ and $d(s) \leq 0$ for all $s>\widetilde{s}$, where both inequalities are strict over sets of positive measure. The rest of the argument is now identical to that in Proposition 2. Q.E.D.

Proof of Proposition 4. By Proposition 3 an increase in $\gamma$ allows to make the CEO's compensation strictly steeper to the right of the threshold $\widehat{s}$, which is also strictly optimal. ${ }^{40}$ It remains to prove that implementing a given $\theta^{*}$ requires a lower severance pay as $\gamma$ increases.

For this we totally differentiate (1), which determines $\theta^{*}$, and also the constraint (6) to obtain (holding $\theta^{*}$ fixed) the derivative

$$
\frac{d W}{d \gamma}=\frac{\int_{\theta^{*}}^{\bar{\theta}}\left[\int_{\widehat{s}}^{\bar{s}}\left[[1-G \theta(\widehat{s})]\left[1-G_{\theta^{*}}(s)\right]-\left[1-G_{\theta^{*}}(\widehat{s})\right][1-G \theta(s)]\right] d s\right] f(\theta) d \theta}{\int_{\theta^{*}}^{\bar{\theta}}\left[G_{\theta^{*}}(\widehat{s})-G \theta(\widehat{s})\right] f(\theta) d \theta} .
$$

\footnotetext{
${ }^{40}$ Holding either $\theta^{*}$ or $W$ fixed, to keep (4) binding the threshold $\widehat{s}$ will shift to the right as $\gamma$ increases.
} 
The denominator of (10) is positive as $G \theta(s)$ satisfies First-Order Stochastic Dominance, which is implied by MLRP. Next, to see that the numerator is negative note that $[1-G \theta(s)] /\left[1-G_{\theta^{*}}(s)\right]$ is strictly increasing in $s$ for all $\theta>\theta^{*}$, which is again implied by MLRP. ${ }^{41}$ Q.E.D.

Proof of Proposition 5. Totally differentiating the condition (1), which pins down $\theta^{*}$, and the constraint (6) while substituting the optimal on-the-job compensation from Proposition 3 yields

$$
\frac{d \theta^{*}}{d W}=-\frac{1}{\gamma} \frac{\int_{\theta^{*}}^{\bar{\theta}}\left[G_{\theta^{*}}(\widehat{s})-G_{\theta}(\widehat{s})\right] f(\theta) d \theta}{\left[\int_{\widehat{s}}^{\bar{s}} \frac{d G_{\theta^{*}(\widehat{s})}}{d \theta^{*}} d s\right]\left[\int_{\theta^{*}}^{\bar{\theta}}\left[1-G_{\theta}(\widehat{s})\right] f(\theta) d \theta\right]} .
$$

To determine the sign of (11), note that MLRP implies First-Order Stochastic Dominance such that $G \theta(s)$ is decreasing in $\theta$ for all $s \in(\underline{s}, \bar{s})$. This yields that $d \theta^{*} / d W>0$.

Consider next the claim that $\theta^{*}<\theta_{F B}$. Totally differentiating (1) and (6) while substituting the optimal on-the-job compensation from Proposition 3 yields

$$
\frac{d \widehat{s}}{d W}=-\frac{1}{\gamma} \frac{1-F\left(\theta^{*}\right)}{\int_{\theta^{*}}^{\bar{\theta}}[1-G \theta(\widehat{s})] f(\theta) d \theta},
$$

We next differentiate (2) with respect to $W$ and substitute for $d \widehat{s} / d W$ from (12). This yields the derivative

$$
-\frac{d \theta^{*}}{d W} f\left(\theta^{*}\right)\left[E\left[s \mid \theta^{*}\right]-V\right]-1
$$

which yields the first-order condition

$$
E\left[s \mid \theta^{*}\right]-V=\frac{-F\left(\theta^{*}\right)}{f\left(\theta^{*}\right)\left(d \theta^{*} / d W\right)} .
$$

Using that $d \theta^{*} / d W>0$ from (11), we have at an interior solution that $E\left[s \mid \theta^{*}\right]-V<0$ and thus that $\theta^{*}<\theta_{F B}$. Q.E.D.

Proof of Proposition 7. We can again restrict consideration to on-the-job pay schemes $w(s, \theta)$ that are strictly increasing at some $s$. Given that all $w(s, \theta)$ are thus strictly increasing somewhere and that $G \theta(s)$ satisfies MLRP, the truthtelling constraint implies again that $\Theta_{-}=$

\footnotetext{
${ }^{41} \mathrm{As} G_{\theta}(s)$ is differentiable, this is equivalent to requiring that $g_{\theta}(s) /\left[1-G_{\theta}(s)\right]$ is strictly decreasing in $\theta$ for any given $s \in(\underline{s}, \bar{s})$. This is commonly referred to as the Monotone Hazard Rate Property, which is implied by MLRP. Further, to obtain this expression we used that by partial integration $E[w(s) \mid \theta]=\gamma \int_{\widehat{s}}^{\bar{s}}\left[1-G_{\theta}(s)\right] d s$.
} 
$\left[\underline{\theta}, \theta^{*}\right)$ and $\Theta_{+}=\left[\theta^{*}, \bar{\theta}\right]$ with $E\left[w\left(s, \theta^{*}\right) \mid \theta^{*}\right]=W$. The following auxiliary result follows now immediately from the proof of Proposition 2.

Claim 1. Take two different feasible pay schemes $\widetilde{w}(s)$ and $\widehat{w}(s)$ such that $\widehat{w}(s)=0$ for $s<\widehat{s}$ and $\widehat{w}(s)=s$ for $s \geq \widehat{s}$. Then if $E\left[\widehat{w}(s) \mid \theta^{\prime}\right] \geq E\left[\widetilde{w}(s) \mid \theta^{\prime}\right]$ holds for some $\theta^{\prime}<\bar{\theta}$, it holds strictly for all $\theta>\theta^{\prime}$.

To complete the proof, we distinguish between two cases. If $w\left(s, \theta^{*}\right)$ satisfies $w\left(s, \theta^{*}\right)=0$ for $s<\widehat{s}$ and $w\left(s, \theta^{*}\right)=s$ for $s \geq \widehat{s}$, Claim 1 and truthtelling imply that the same contract is chosen for all $\theta \geq \theta^{*}$. That is, the menu is then degenerate with $w(s, \theta)=w\left(s, \theta^{*}\right)$. Suppose next that $w\left(s, \theta^{*}\right)$ has a different form. As in the proof of Proposition 2, we can then construct a single offer $\widehat{w}(s)$ satisfying $\widehat{w}(s)=0$ for $s<\widehat{s}$ and $\widehat{w}(s)=s$ for $s \geq \widehat{s}$ such that the same cutoff $\theta^{*}$ is implemented while the constraint (4) is relaxed. This follows as for all $\theta>\theta^{*}$ we have that $E[\widehat{w}(s) \mid \theta]>E[w(s, \theta) \mid \theta]$, which in turn follows immediately from Claim 1 and the truthtelling requirement for the original menu. As in Proposition 2, we can then adjust the new (single) on-the-job pay scheme $\widehat{w}(s)$ so as to implement $\theta^{*}$ with a lower severance pay. Q.E.D.

Proof of Proposition 8. We show that the optimal choice of $W$ is strictly increasing in $V$, which by (11) implies that the corresponding optimal choice of $\theta^{*}$ is also strictly increasing. Implicit differentiation of the first-order condition for $W$ in (14) gives

$$
\frac{d W}{d V}=-\frac{f\left(\theta^{*}\right)\left(d \theta^{*} / d W\right)}{S O C}>0
$$

where $S O C<0$ represents the second-order condition, which must be satisfied at an interior optimum. Q.E.D.

Proof of Proposition 9. We show that the optimal choice of $W$ is strictly increasing in $\alpha$, which by (11) implies that the corresponding optimal choice of $\theta^{*}$ is also strictly increasing. Note first that the first-order condition (14) now transforms to

$$
\alpha\left[E\left[s \mid \theta^{*}\right]-V\right]=\frac{-F\left(\theta^{*}\right)}{f\left(\theta^{*}\right)\left(d \theta^{*} / d W\right)},
$$

where we can again substitute $d \theta^{*} / d W$ from (11). Implicit differentiation of (15) gives

$$
\frac{d W}{d \alpha}=\frac{E\left[s \mid \theta^{*}\right]-V}{S O C}>0
$$


where we used from Proposition 5 that $\theta^{*}<\theta_{F B}$ at the optimum and that the second-order condition at the optimum requires that $S O C<0$. Q.E.D.

Proof of Proposition 10. We show first that to implement a given cutoff $\theta^{*}$, the higher $B$ the higher must be the respective severance pay $W$. We totally differentiate (1), which determines $\theta^{*}$, and the constraint (6) to obtain

$$
\frac{d W}{d B}=\frac{1-G_{\theta^{*}}(\widehat{s})}{\int_{\theta^{*}}^{\bar{\theta}}\left[G_{\theta^{*}}(\widehat{s})-G \theta(\widehat{s})\right] f(\theta) d \theta}>0,
$$

where the sign follows again from MLRP of $G \theta(s)$, which implies First-Order Stochastic Dominance.

Take now some value $B=\widehat{B}$. The optimal contract specifies a severance pay $W=\widehat{W}$ and an on-the-job pay $w(s)=\widehat{w}(s)$, which is in turn characterized by some cutoff (or "strike price") $\widehat{s}=\widehat{s}$. Denote also the resulting cutoff by $\theta^{*}=\widehat{\theta}^{*}$. If private benefits are higher and equal to $B=\widetilde{B}>\widehat{B}$, we know from (16) that in order to obtain the same cutoff $\theta^{*}=\widehat{\theta}^{*}$ the severance pay must be strictly higher: $W=\widetilde{W}>\widehat{W}$. To still satisfy the incentive constraint (6), this requires that also the on-the-job pay $\widetilde{w}(s)$ must become more attractive to the CEO, i.e., the respective cutoff $\widehat{s}=\widehat{s}^{\prime \prime}$ must satisfy $\widehat{s}^{\prime \prime}<\widehat{s}^{\prime}$.

Consider next the derivative (13) of the objective function. By construction, we have for $B=\widehat{B}, \widehat{s}=\widehat{s}^{\prime}, W=\widehat{W}$, and $\theta^{*}=\widehat{\theta}^{*}$ that the derivative is just zero. (This is just the firstorder condition.) We now want to sign the derivative if we substitute, instead, $B=\widetilde{B}, \widehat{s}=\widehat{s}^{\prime \prime}$, $W=\widetilde{W}$, and $\theta^{*}=\widehat{\theta}^{*}$, i.e., at the point where with higher benefits the same cutoff is achieved, albeit with a higher severance pay and a higher on-the-job pay. More precisely, we want to show that the derivative (13) is then negative. From inspection of (13) this is the case if at the cutoff $\theta^{*}=\widehat{\theta}^{*}$ the derivative $d \theta^{*} / d W$ is strictly lower for the case where we have $B=\widetilde{B}$ and thus $W=\widetilde{W}$ and $\widehat{s}=\widehat{s}^{\prime \prime}$. Given that $\widehat{s}^{\prime \prime}<\widehat{s}^{\prime}$ this in turn holds if the derivative (11) is strictly increasing in $\widehat{s}$. To show that this is the case, we rearrange (11) to obtain

$$
\frac{d \theta^{*}}{d W}=\frac{1}{\gamma}\left(\frac{-1}{\int_{\widehat{s}}^{\bar{s}} \frac{d G_{\theta^{*}}(s)}{d \theta^{*}} d s}\right)\left(\frac{\int_{\theta^{*}}^{\bar{\theta}}\left[G_{\theta^{*}}(\widehat{s})-G_{\theta}(\widehat{s})\right] f(\theta) d \theta}{\left[\int_{\theta^{*}}^{\bar{\theta}}\left[1-G_{\theta}(\widehat{s})\right] f(\theta) d \theta\right]}\right) .
$$

The first term of (17) in round brackets is positive and by $d G_{\theta^{*}}(\widehat{s}) / d \theta^{*}<0$, which is implied by First-Order Stochastic Dominance and thus by MLRP, strictly increasing in $\widehat{s}$. Next, after some transformations we have that the sign of the derivative of the last term in (17) w.r.t. $\widehat{s}$ is determined by the expression 


$$
\int_{\theta^{*}}^{\bar{\theta}}\left[g_{\theta^{*}}(\widehat{s})[1-G \theta(\widehat{s})]-g \theta(\widehat{s})\left[1-G_{\theta^{*}}(\widehat{s})\right]\right] f(\theta) d \theta .
$$

That (18) is also strictly positive follows again from MLRP, by which $g \theta(s) /[1-G \theta(s)]$ must be strictly decreasing in $\theta$ for all $s \in(\underline{s}, \bar{s}) .{ }^{42}$ Hence, we have shown that given $B=\widetilde{B}$, if we evaluate (13) at the value $W=\widetilde{W}$ where we have $\theta^{*}=\widehat{\theta}^{*}$, then the derivative is strictly negative. Given strict quasiconcavity of the objective function and the assumption that the optimal $\theta^{*}$ (and thus, in particular, $\widehat{\theta}^{*}$ ) is interior, we thus have that for $B=\widetilde{B}$ the optimal level of the severance pay is strictly lower than $W=\widetilde{W}$. But this finally implies that under the optimal contract there is more entrenchment if $B=\widetilde{B}$ than if $B=\widehat{B}<\widetilde{B}$. Q.E.D.

\section{References}

Adams, Renée B. and Daniel Ferreira, 2003, A Theory of Friendly Boards, mimeo, Federal Reserve Bank of New York.

Almazan, Andres and Javier Suarez, 2003, Entrenchment and Severance Pay in Optimal Governance Structures, Journal of Finance 58, 519-548.

Andrade, Gregor, Mark Mitchell, and Erik Stafford, 2001, New Evidence and Perspectives on Mergers, Journal of Economic Perspectives 15, 103-120.

Barker, Vincent L., III and Irene M. Duhaime, 1997, Strategic Change in the Turnaround Process: Theory and Empirical Evidence, Strategic Management Journal 18, 13-38.

Bebchuk, Lucian A. and Jesse M. Fried, 2004, Pay Without Performance. Cambridge, MA: Harvard University Press.

Bebchuk, Lucian A. and Yaniv Grinstein, 2005, The Growth of Executive Pay, Oxford Review of Economic Policy 21, 283-303.

Bebchuk, Lucian A., Alma Cohen, and Allen Ferrell, 2004, What Matters in Corporate Governance? mimeo, Harvard Law School.

\footnotetext{
${ }^{42}$ This is commonly referred to as the Monotone Hazard Rate Property, which is stronger than First-Order Stochastic Dominance but weaker than MLRP.
} 
Coffee, John C., Jr., 2003, What Caused Enron? A Capsule Social and Economic History of the 1990's, mimeo, Columbia Law School.

Conyon, Martin J., 1997, Corporate Governance and Executive Compensation, International Journal of Industrial Organization 15, 493-509.

Core, John E., Robert W. Holthausen, and David F. Larcker, 1999, Corporate Governance, Chief Executive Officer Compensation, and Firm Performance, Journal of Financial Economics 51, 371-406.

Crawford, Anthony J., John R. Ezzell, and James A. Miles, 1995, Bank CEO Pay-Performance Relations and the Effects of Deregulation, Journal of Business, 68, 231-256.

Cyert, Richard M., Sok-Hyon Kang, and Praveen Kumar, 2002, Corporate Governance, Takeovers, and Top-Management Compensation: Theory and Evidence, Management Science 48, 453469.

Daines, Robert, Vinair B. Nair, and Lewis Kornhauser, 2005, The Good, the Bad, and the Lucky: CEO Pay and Skill, mimeo, University of Pennsylvania.

DeMarzo, Peter M., and Darrel Duffie, 1999, A Liquidity-Based Model of Security Design, Econometrica 67, 65-99.

Dial, Jay and Kevin J. Murphy, 1995, Incentives, Downsizing, and Value Creation in General Dynamics, Journal of Financial Economics 37, 261-314.

Dow, James and Clara C. Raposo, 2005, CEO Compensation, Change, and Corporate Strategy, forthcoming in Journal of Finance.

DTI, 2003, Rewards for Failure: Directors' Remuneration-Contracts, Performance and Severance, Department of Trade and Industry, London

Eisfeldt, Andrea L. and Adriano A. Rampini, 2004, Letting Go: Managerial Incentives and the Reallocation of Capital, mimeo, Northwestern University.

Gordon, Shelley S., Wayne H. Stewart, Robert Sweo, and William A. Luker, 2000, Convergence Versus Strategic Reorientation: The Antecedents of Fastpaced Organizational Change, Journal of Management 26, 911-945. 
Hall, Brian J. and Jeffrey B. Liebman, 1998, Are CEOs Really Paid Like Bureaucrats? Quarterly Journal of Economics 113, 653-691.

Hambrick, Ronald C., Marta A. Geletkanycz, and James W. Fredrickson, 1993, Top Executive Commitment to the Status Quo: A Test of Some of Its Determinants, Strategic Management Journal 14, 401-418.

Harris, Ellie G., 1990, Antitakeover Measures, Golden Parachutes, and Target Firm Shareholder Welfare, Rand Journal of Economics 21, 614-625.

Hermalin, Benjamin E., 2004, Trends in Corporate Governance, forthcoming in Journal of Finance.

Hermalin, Benjamin E. and Michael S. Weisbach, 1998, Endogenously Chosen Boards of Directors and Their Monitoring of the CEO, American Economic Review 88, 96-118.

Hermalin, Benjamin E. and Michael S. Weisbach, 2003, Boards of Directors as an Endogenously Determined Institution: A Survey of the Economic Evidence, Economic Policy Review 9, $7-26$.

Holmström, Bengt R. and Steven N. Kaplan, 2001, Corporate Governance and Merger Activity in the United States: Making Sense of the 1980s and 1990s, Journal of Economic Perspectives 15, 121-144.

Hubbard, R. Glenn and Darius Palia, 1995, Executive Pay and Performance: Evidence from the U.S. Banking Industry, Journal of Financial Economics 39, 105-130.

Huson, Mark R., Robert Parrino, and Laura Starks, 2001, Internal Monitoring Mechanisms and CEO Turnover: A Long-Term Perspective, Journal of Finance 56, 2265-2297.

Innes, Robert D., 1990, Limited Liability and Incentive Contracting with Ex-Ante Action Choices, Journal of Economic Theory 52, 45-67.

Jensen, Michael C., 1993, The Modern Industrial Revolution, Exit, and the Failure of Internal Control Systems, Journal of Finance 48, 831-880.

Lambert, Richard A., 1986, Executive Effort and the Selection of Risky Projects, Rand Journal of Economics 17, 77-88. 
Lambert, Richard A. and David F. Larcker, 1985, Golden Parachutes, Executive DecisionMaking, and Shareholder Wealth, Journal of Accounting and Economics 7, 179-203.

Lefanowicz, Craig E., John R. Robinson, and Reed Smith, 2000, Golden Parachutes and Managerial Incentives in Corporate Acquisitions: Evidence from the 1980s and 1990s, Journal of Corporate Finance 6, 215-239.

Mehran, Hamid, George E. Nogler, and Kenneth B. Schwartz, 1997, CEO Incentive Plans and Corporate Liquidation Policy, Journal of Financial Economics 50, 319-349.

Milgrom, Paul R., 1981, Good News and Bad News: Representation Theorems and Applications, Bell Journal of Economics 12, 380-391.

Murphy, Kevin J., 1999, Executive Compensation, in Orley Ashenfelter and David Card (eds.): Handbook of Labor Economics, Vol. 3. Amsterdam: North Holland.

Murhpy, Kevin J. and Jan Zábojník, 2004, Managerial Capital and the Market for CEOs, mimeo, University of Southern California.

Nachman, David C. and Thomas H. Noe, 1994, Optimal Design of Securities under Asymmetric Information, Review of Financial Studies 7, 1-44.

Rotemberg, Julio J. and Garth Saloner, 2000, Visionaries, Managers, and Strategic Direction, Rand Journal of Economics 31, 693-716.

Scharfstein, David S. and Jeremy C. Stein, 2000, The Dark Side of Internal Capital Markets: Divisional Rent-Seeking and Inefficient Investment, Journal of Finance 55, 2537-2564.

Schwab, Stewart J. and Randall S. Thomas, 2004, What Do CEOs Bargain For? An Empirical Study of Key Legal Components of CEO Contracts, mimeo, Cornell Law School.

Shleifer, Andrei and Robert W. Vishny, 1989, Management Entrenchment: The Case of ManagerSpecific Investments, Journal of Financial Economics 25, 123-139.

Song, Fenghua and Anjan V. Thakor, 2004, Information Control, Career Concerns, and Corporate Governance, mimeo, Washington University.

Walker, David I., 2005, The Manager's Share, mimeo, Boston University School of Law. 
Warner, Jerold B., Ross L. Watts, and Karen H. Wruck, 1988, Stock Prices and Management Changes, Journal of Financial Economics 20, 461-192.

Yermack, David, 2004, Golden Handshakes: Rewards for CEOs Who Leave, mimeo, New York University. 